\title{
An analytical study of efficiency use of agricultural economic resources of wheat production in Sohag governorate, Egypt
}

\author{
Al-Banani M. A. E., Al-Shishiny A. S., Osman B. H. M.* \\ Department of Agricultural Economics, Faculty of Agriculture, Al-Azhar University, Assiut, Egypt
}

\begin{abstract}
Wheat is considered the most important food grain crop produced in Egypt at the level of domestic consumption and the list of food imports. As the number one strategic crop due to food security considerations, wheat is the staple food for both rural and urban population. Like other agricultural products, wheat is influenced by agricultural policies adopted by the government and direct and indirect intervention in production, pricing and imports. The research aims to estimate the efficiency of use agricultural economic resources for production wheat crop in Sohag governorate, Egypt to identify extent of scarcity and deviation of several resources used in production of wheat crop, besides estimate costs of using these resources structure of inputs in production process of wheat, also identify the degree of achieving different efficiency of inputs for production process over statistical estimates of production functions, to find the extent of which economic efficiency has been reached in the different holding categories determined the application of some total and relative criteria to measure that efficiency for the study sample. The results showed that the percentage of variable costs reached $55.8 \%$, achieved this ratio both production of production supplies and labor nearly $14.8 \%$ and $41 \%$, respectively, of total costs. In addition, the quantity of seeds, chemical fertilizers, labor wages and machinery are the most important variables that impact the total production of wheat in the study sample. While volume of production which reduce average costs about 16.8 Ardeb (Ardeb $=5.44$ imperial or 5.619 U.S. bushels), also actual average production was 17.5 Ardeb, and economic efficiency was not achieved due to there was wastage in the use of resources.
\end{abstract}

Keywords: inputs, optimal use, economic efficiency, absolute standards, relative standards.

* Corresponding author: Osman B. H. M.,

E-mail address: balegh20202@gmail.com 


\title{
كفاءة استخدام الموارد الاقتصادية الزراعية فى إنتاج محصول القمح بمحافظة سوهاج بجمهورية مصر العربية
}

\author{
محمد أبو العلا البناني، أيمن سعيد الثيشينى، بليغ حمدى محمد عثمان \\ قسم الاقتصاد الزراعي ، كلية الزر اعة ، جامعة الأزهر (فرع أسبوط) ، أسيوط ، جمهورية مصر العربية
}

المستخلص

يعتبر محصول القمح من المحاصيل الإستر اتيجية، حيث يحتل مرتبة كبيرة في خريطة استهلاك الفرد المصري، كما أن المتغيرات الاقتصادية

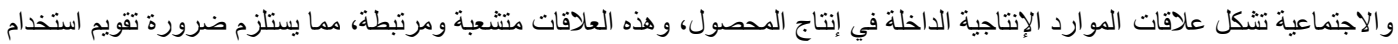

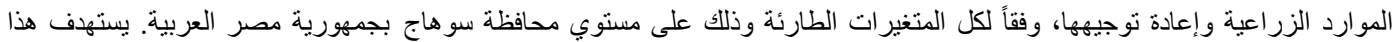

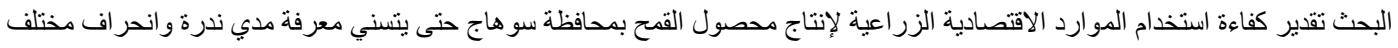

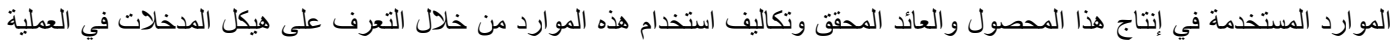

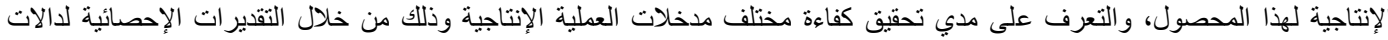

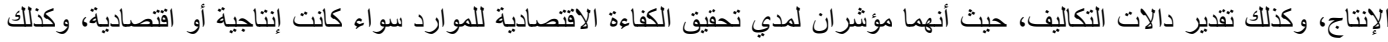

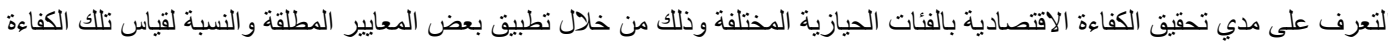

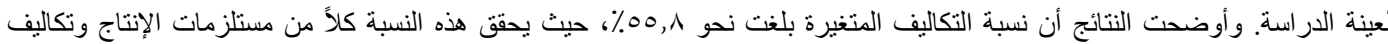

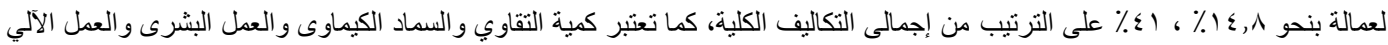

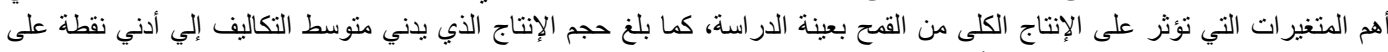

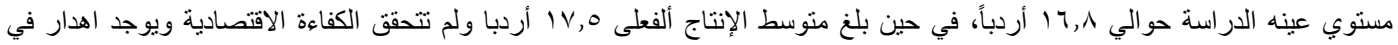
استخدام الموارد. 


\section{الهـف من البحث}

يستهدف هذا البحث بصفة رئيسية التعرف على مدى ندرة

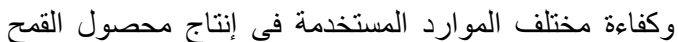
والعائد المحقق وتكاليف استخدام هذه المواردة التهاجة من خلال مجمو عة من الأهداف الفر عية التالية:

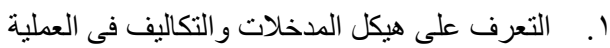

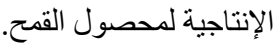

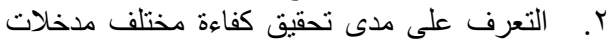

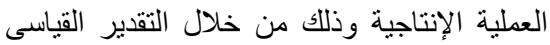

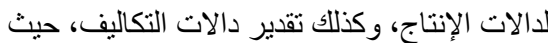
تستخدم بعض مشتقاتهما الاقتصادية كمؤشرات الات الاتئات

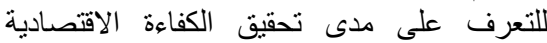
للمو ارد سو اء الإنتاجية أو الاقتصادية. r. التعرف على مدى تحقيق الكفاءة الاقتصادية الإنية بالفئات الحيازية المختلفة، وذلكئك من خلال تطبيق الكيق بعض المعايير المطلقة و النسبية لقياس تلك الكفاءة.

\section{الطريقة البحثية ومصادر جمع البيانات}

تحقيقاً لأهداف البحث اعتمد هذا البحث على أسلوبي التحليل

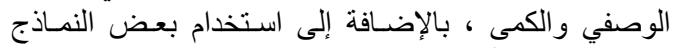

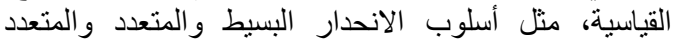

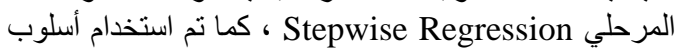

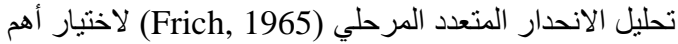

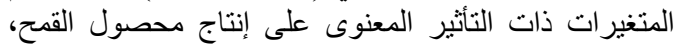

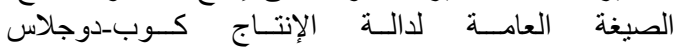
:(Leftwich, 1996)

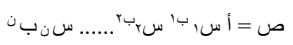

الصيغة الخطية (اللو غاريتمية المزدوجة):

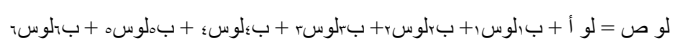

$$
\text { حيث أن : }
$$

$$
\text { لو ص: اللو غاريتم الطبيعي لإنتاج القمح (بالأردب). }
$$

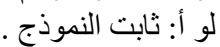

لو سا: اللو غاريتم الطبيعي لكمية التقاوي (بالكيلو جرام ). لو سب: اللوغاريتم الطبيعي لكمية السماد الكيماوى (بالمادة (لكية

ألفعالة).

لو سب: اللو غاريتم الطبيعي للعمل الآلي( بالساعة) .

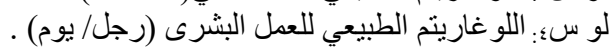

لو سه: اللو غارينم الطبيعي لكمية المبيدات (باللتر) ).

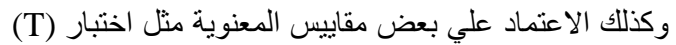

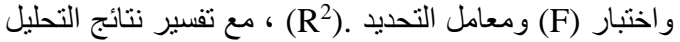

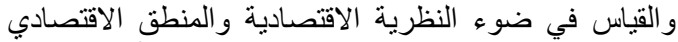
(Porkin, 1996) و واعنمد هذا البحث بصنة أساسية على الإئى
مقدمة - مقة

يعتبر قطاع الزر اعة من القطاعات التي لها دور اً رئيسياً وهاماً

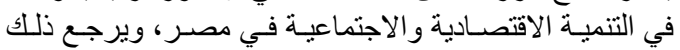

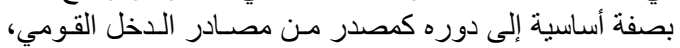

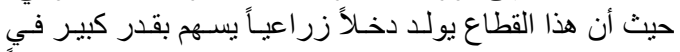

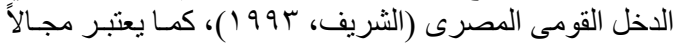

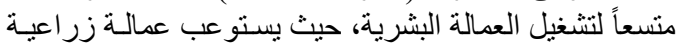

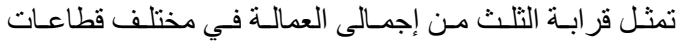

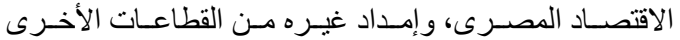

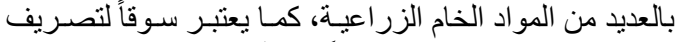

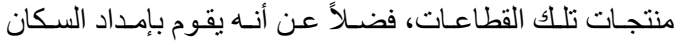
باحتياجاتهم الأساسية من المو اد الغذائية، بالإضافة إلى الفى حصيلة

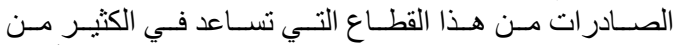

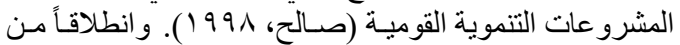

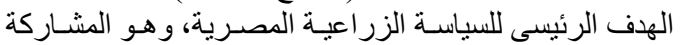

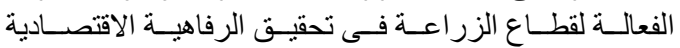

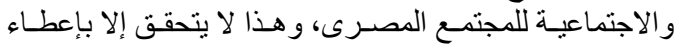

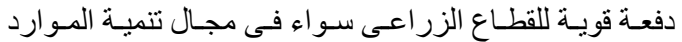

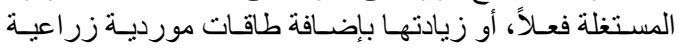

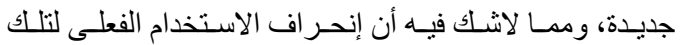

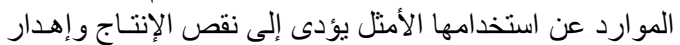

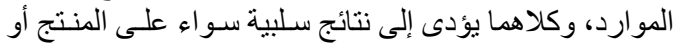

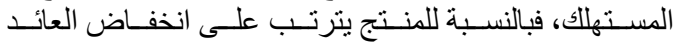

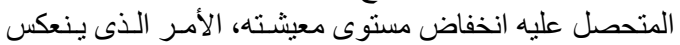

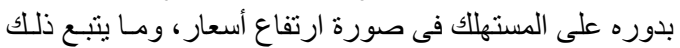

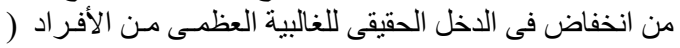

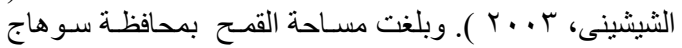

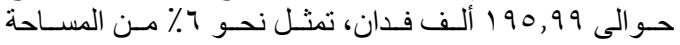

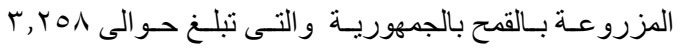

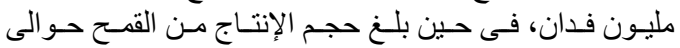

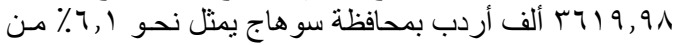

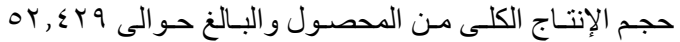

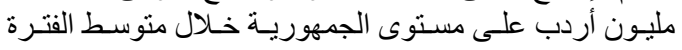

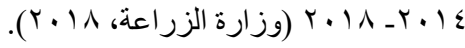

\section{مشكلة البحث}

يعتبر محصول القمح من المحاصيل الاستـر اتيجية، كمـا يعتبر

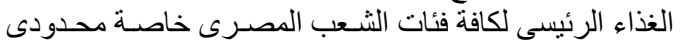

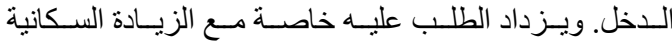

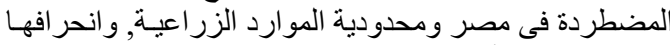

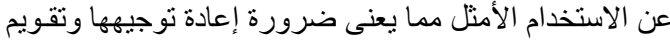

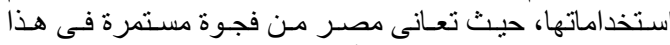

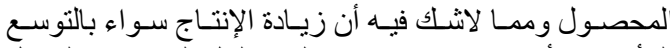

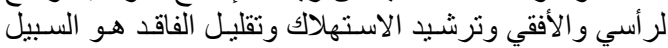
لزيادة نسبة الاكتفاء الذاتي وتقليل ألفجوة الغذائية منه. 


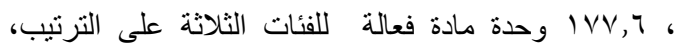

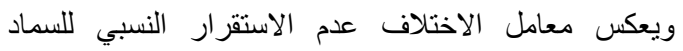

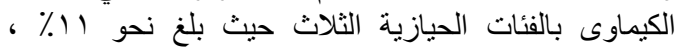

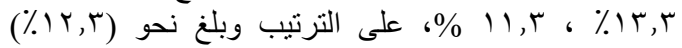

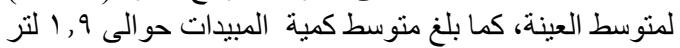

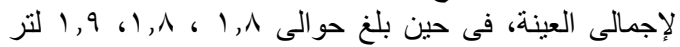

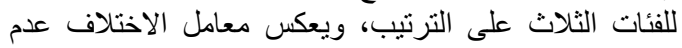

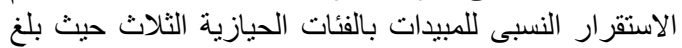

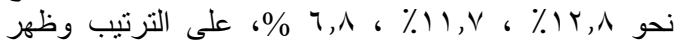

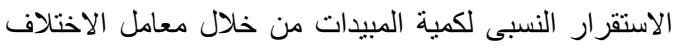

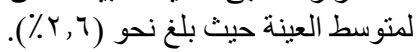

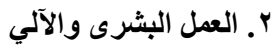

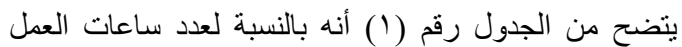

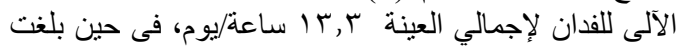

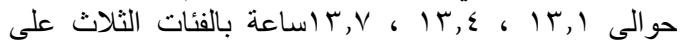

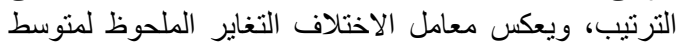

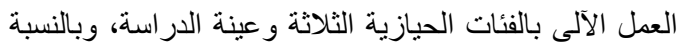

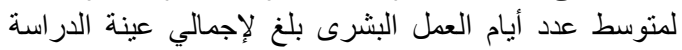

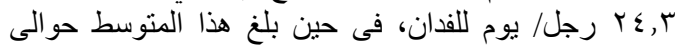

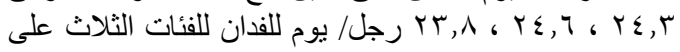

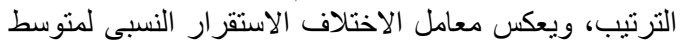

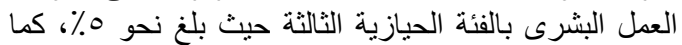
يعكس التباين الملحوظ في الفئة الفئات الحيازية الأولى والثانية و على مستوى العينة.

\section{r. - ممية الإنتاج}

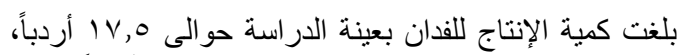

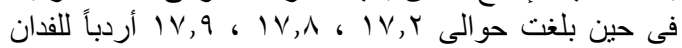

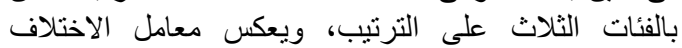

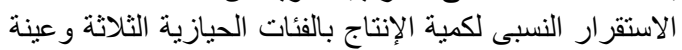

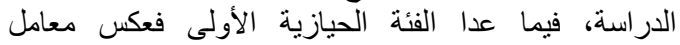

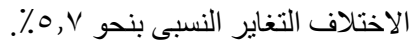

البيانات الثانوية المنشورة وغير المنشورة التي تصدرها

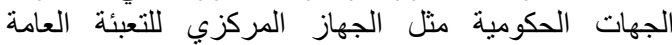

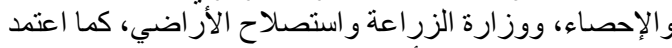

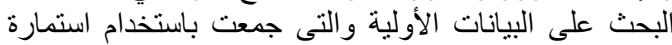

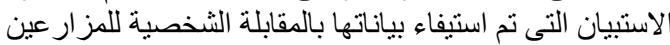

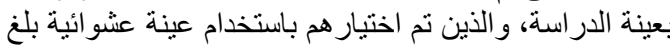

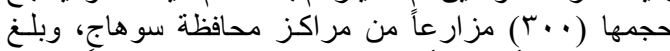

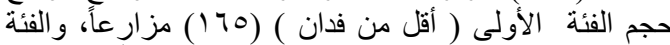

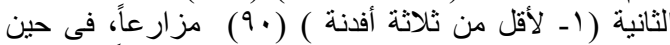

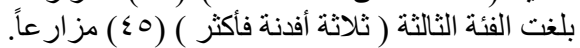

\section{النتائج ومناقشتها}

\section{أولا: المدخلات وهيكل التكاليف الإتتاجية لمحصول القمح}

يتتاول هذا الجزء المدخلات الإنتاجية الفيزيقية متمثلة في

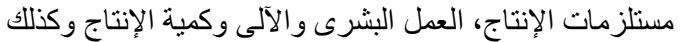

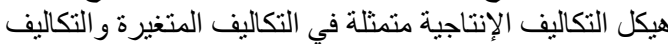
الكلية بعينة الدر اسة بمحافظة سو هاج.

أ. المدخلات الإنتاجية لمحصول القمح

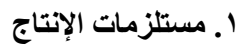

يوضح الجدول رقم (1) بعض المعايير الإحصائية للمدخلات

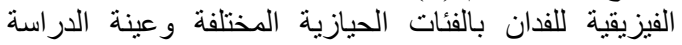

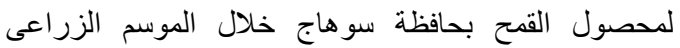

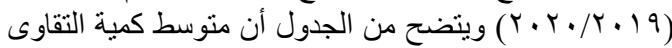

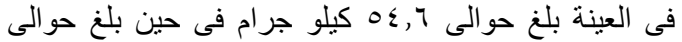

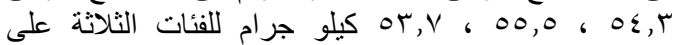

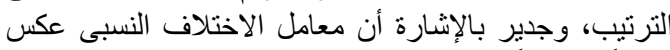

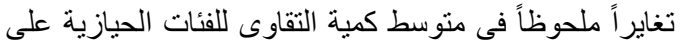

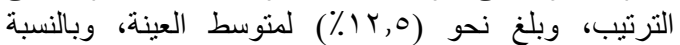

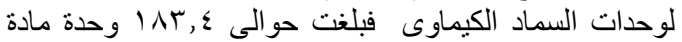

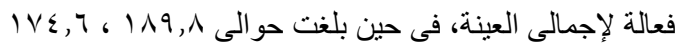

جدول ( ) : متوسط كميات العناصر الإنتاجية ومعامل الاختلاف للفئات الحيازية لمحصـول القهـح بعينـة الدر اسـة بمحافظـة سـوهاج خـلال

\begin{tabular}{|c|c|c|c|c|c|c|c|c|c|}
\hline \multicolumn{2}{|c|}{ العينة } & \multicolumn{2}{|c|}{ الفئة الثالثة } & \multicolumn{2}{|c|}{ الفئة الثانية } & \multicolumn{2}{|c|}{ الفئة الأولى } & \multirow[b]{2}{*}{ الوحدة } & \\
\hline الاختلاف & متوسطة & الاختلامل & متوسط & الاختلاف & متوسطة & الاختلامل & متوسطة & & \\
\hline$\varepsilon, q$ & $i v, 0$ & $r, r$ & $1 v, 9$ & $r, r$ & $i v, \lambda$ & $0, \mathrm{~V}$ & $i V, r$ & أردب & كمية الإنتاج \\
\hline $1 Y, 0$ & $0 \leqslant, 7$ & 10,1 & or,,$y$ & $\pi$ & 00,0 & 11,7 & $0 \leqslant, r$ & كيلو جرام & كمية الثقاوى \\
\hline$T Y, r$ & $\mid \Lambda T, \xi$ & $11, r$ & $W V, T$ & $1 \%, r$ & $T V \varepsilon, 7$ & 11 & $1 / 9,1$ & كجم مادة فعالة & وحدات السماد لكيماوى \\
\hline$T, T$ & 1,9 & 7,1 & 1,9 & $11, \mathrm{v}$ & 1,1 & $\overline{T Y, \Lambda}$ & $1, \lambda$ & باللتز & المبيدات \\
\hline 9,1 & $15, r$ & $7, \mathrm{~V}$ & $1 \%, \mathrm{~V}$ & $\Lambda, Y$ & $1 \%, \varepsilon$ & $1 \cdot, \mathrm{V}$ & $1 \%, 1$ & ساعة/يوم & العمل الآلى \\
\hline 7,7 & $r \varepsilon, r$ & 0 & $r r, \Lambda$ & 7,0 & $r \varepsilon, T$ & 7,7 & $r \varepsilon, r$ & رجل/يوم & العمل البشرى \\
\hline
\end{tabular}

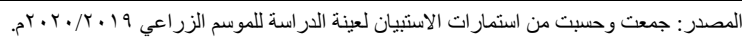




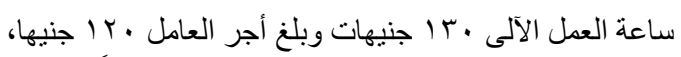

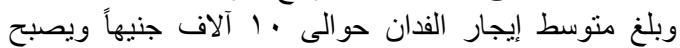

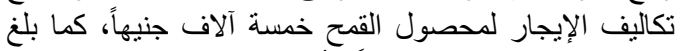

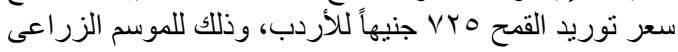
r. r. r. T 19

\section{ب. هيكل التكاليف الإتتاجية لمحصول القمح}

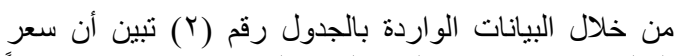

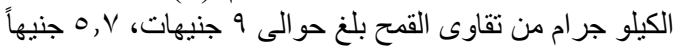

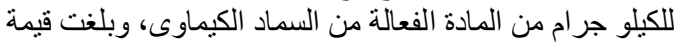

جدول (r) : قيمة العناصر الإنتاجية و الأهمية النسبية لبنودها وفقاً للفئات الحيازية لمحصول القمح بعينـة الدر اسـة بمحافظـة سـوهاج خـلال

\begin{tabular}{|c|c|c|c|c|c|c|c|c|c|c|}
\hline \multicolumn{2}{|c|}{ العينة } & \multicolumn{2}{|c|}{ الفئة الثالثة } & \multicolumn{2}{|c|}{ الفئة الثانية } & \multicolumn{2}{|c|}{ الفئة الأولى } & \multirow{2}{*}{ الوحدة } & \multirow[b]{2}{*}{ 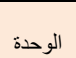 } & \multirow{2}{*}{ العناصر الإنتاجيَّة بيـان } \\
\hline$\%$ & المتوسط & $\%$ & المتوسط & $\%$ & المتوسط & $\%$ & المتوسط & & & \\
\hline$\varepsilon, r$ & $\sum 91, \varepsilon$ & $\varepsilon, r$ & $\varepsilon \Lambda \Gamma, r$ & $\varepsilon, \varepsilon$ & $\sum 99,0$ & $\varepsilon, \Gamma$ & $\varepsilon \lambda \Lambda, Y$ & 9 & كيلوجرام & كمية الثقاوى \\
\hline $9, Y$ & $1, \leqslant 0, \varepsilon$ & $9, \cdot$ & $1.1 r, r$ & $\Lambda, \Lambda$ & $990, Y$ & 9,7 & $1 \cdot 11,9$ & $0, \mathrm{~V}$ & مادة فعالة & وحدات السماد الكيماوى \\
\hline $1, r$ & $1 \leqslant r, 0$ & $1, r$ & $1 \leqslant Y, 0$ & $1, r$ & $1 \% 0$ & $1, r$ & 150 & $v_{0}$ & باللتز & المبيدات \\
\hline $10, r$ & $1 \times r 9$ & 10,1 & $|V \lambda|$ & $10, \varepsilon$ & $I V \leqslant Y$ & 10 & $I V \cdot r$ & $1 \%$. & ساعة ل ماعة & العمل الآلى \\
\hline$r_{0, V}$ & r917 & Yo,r & Y107 & $r 7,1$ & rq0Y & $Y 0, V$ & r917 & $1 \%$. & رجل رجل & العمل البشرى \\
\hline 00,1 & $T r Y \leqslant, r$ & $00, \mathrm{~V}$ & TrVo,1 & 00,1 & TRYT,V & 00,1 & $T r Y \leqslant, T$ & - & - & التكاليف المتغيرة \\
\hline $1 \ldots$ & $11 r r \leqslant, r$ & $1 \ldots$ & IIYVO,1 & $1 \ldots$ & $11 K r, V$ & $1 \ldots$ & $11 T r \varepsilon, T$ & & & التكاليف الكلية \\
\hline
\end{tabular}

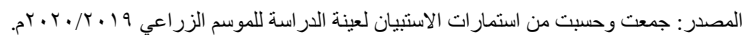

تكاليف مستلزمات الإنتاج، بينما بلغ إجمالى تكاليف العمالة

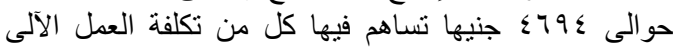

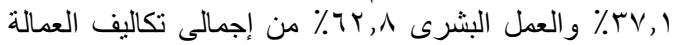

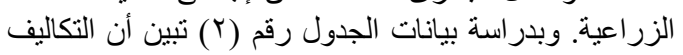

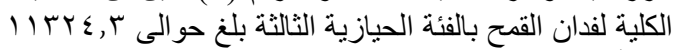

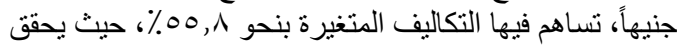

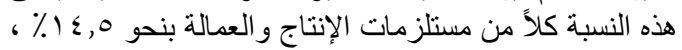

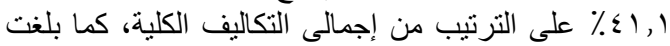

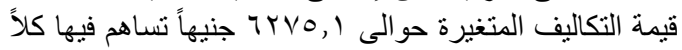

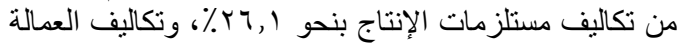

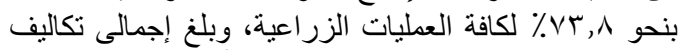

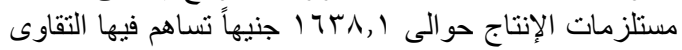

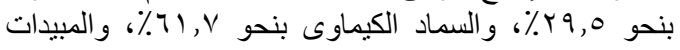

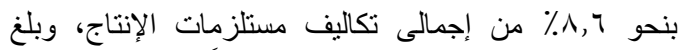

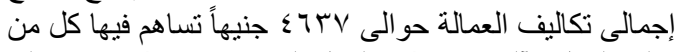

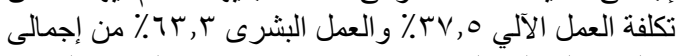

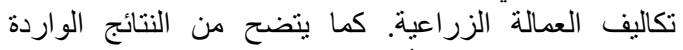

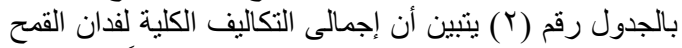

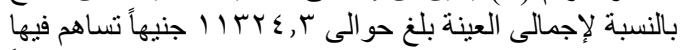

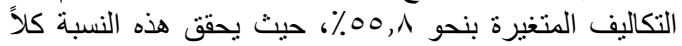

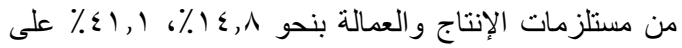

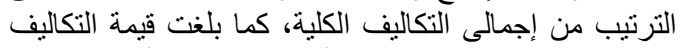

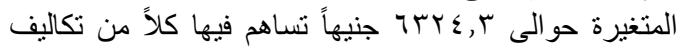

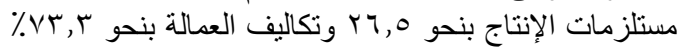

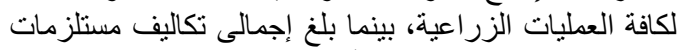

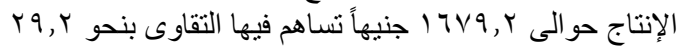

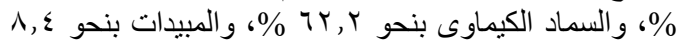
\% من اجمالى تكاليف مستلزمات الإنتاج، كما بلغ اجمالى بند

\section{ج. هيكل التكاليف الإنتاجية لمحصول القمح بعينة الدراسة بمحافظة سوهاج}

بدر اسة الجدول رقم (r) يتبين أن إجمالى التكاليف الكلية لفدان

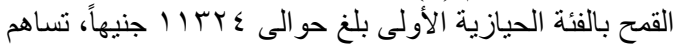

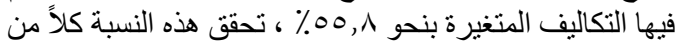

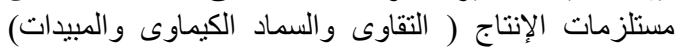

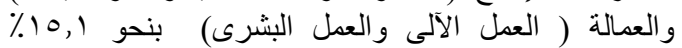

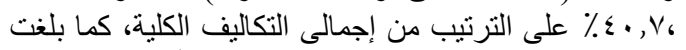

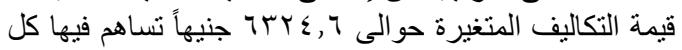

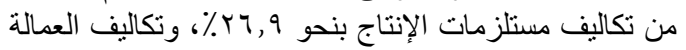

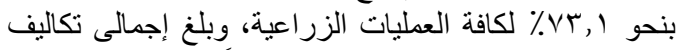

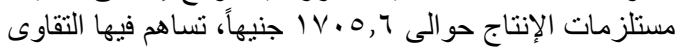

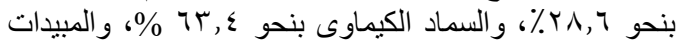

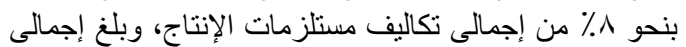

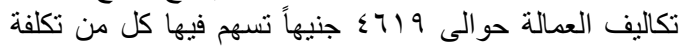

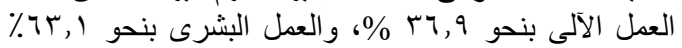

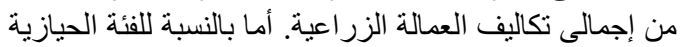

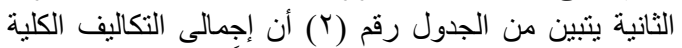

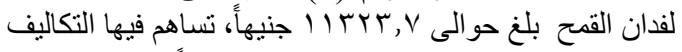

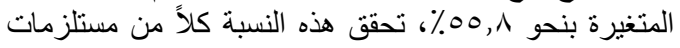

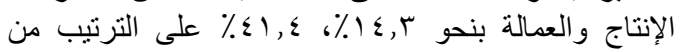

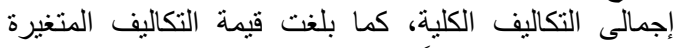

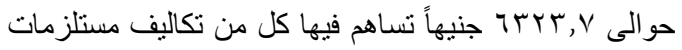

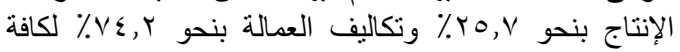

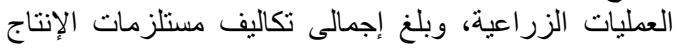

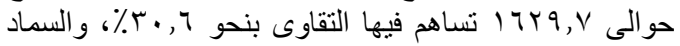

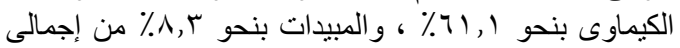


الاقتصادية. أما عن الجدارة الإنتاجية للعناصر الإنتاجية

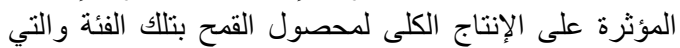

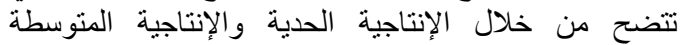

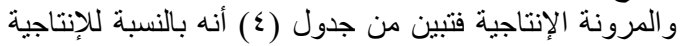

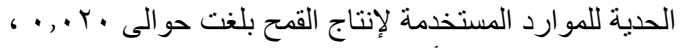

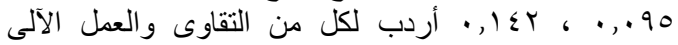

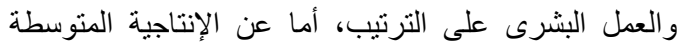

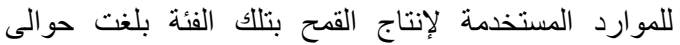
9 q

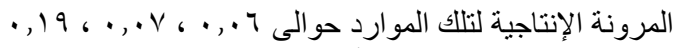

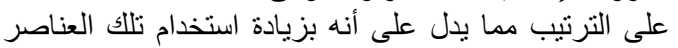

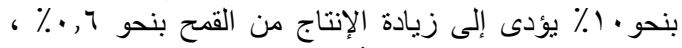

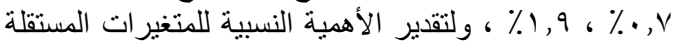

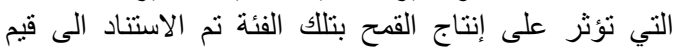

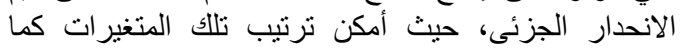

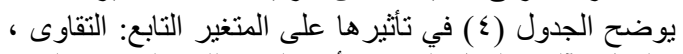

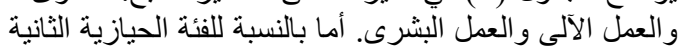

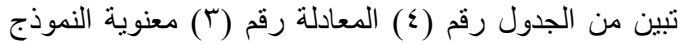

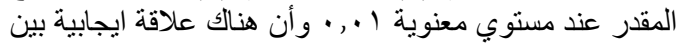

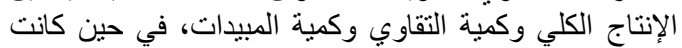

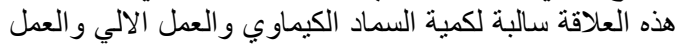

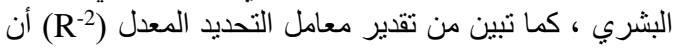

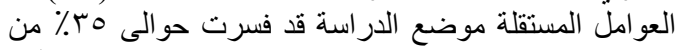

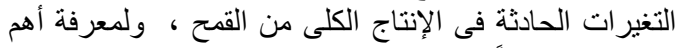

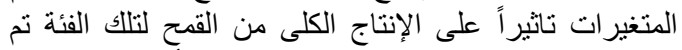

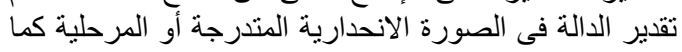

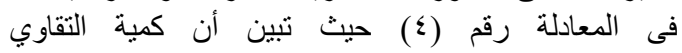

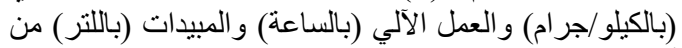

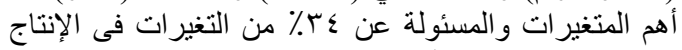

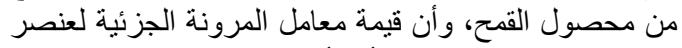

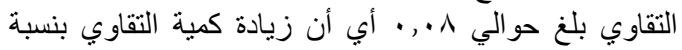

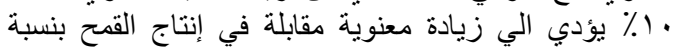

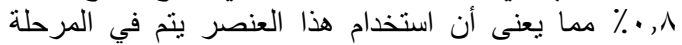

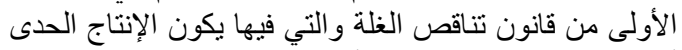

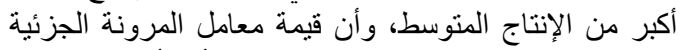

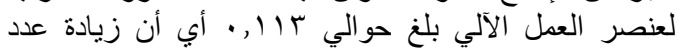

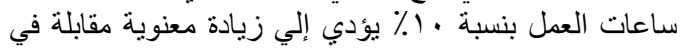

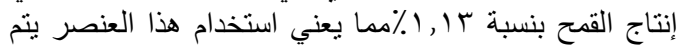

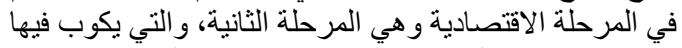

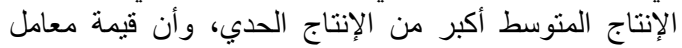

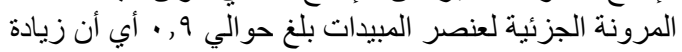

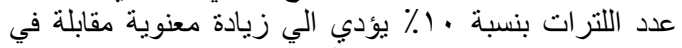

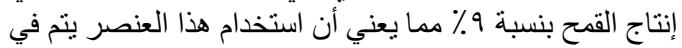
المرحلة الاقتصادية.

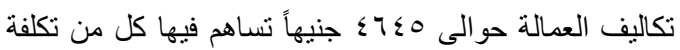

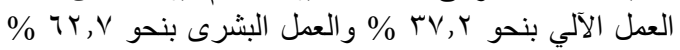
من إجمالى تكاليف العمالة الزر اعية.

\section{ثانيا: الكفاعة الاقتصادية للموارد الزراعية فى إنتاج القمح

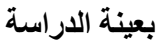

\section{أ. تقدير دالات الإنتاج لمحصول القمح بعينة الدراسة}

يتضمن هذا الجزء قياس الكفاءة الإنتاجية لاستخدام الموارد

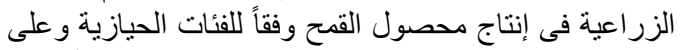

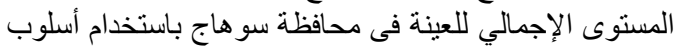

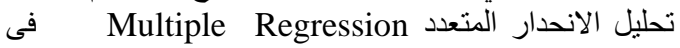

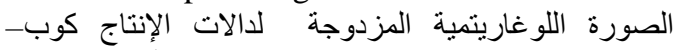
دوجلاس Cobb-Doglas كما تم استخدام أسلوب تحلئ كليل الانحدار المتعدد المرحلي Step-wise Regression لتحديد

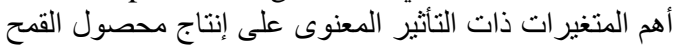

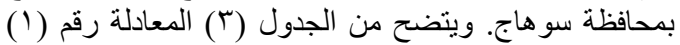

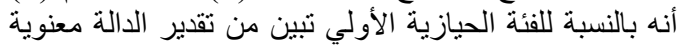

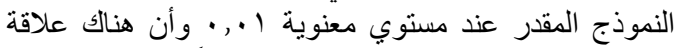

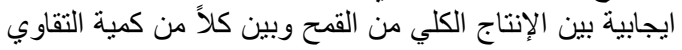

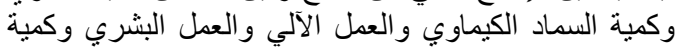

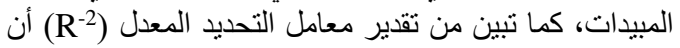

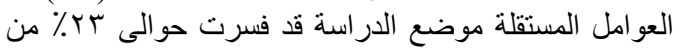

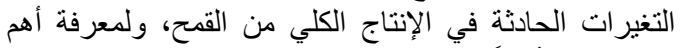

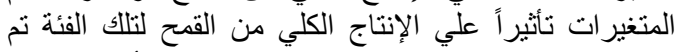

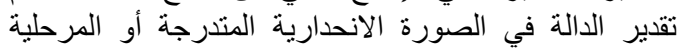

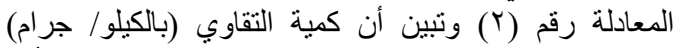

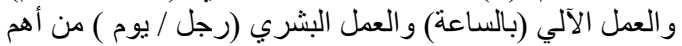

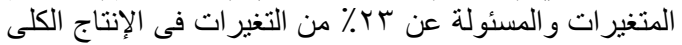

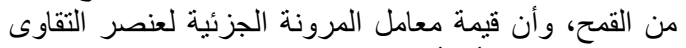

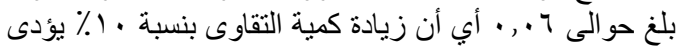

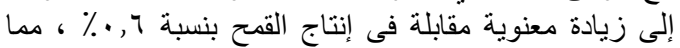

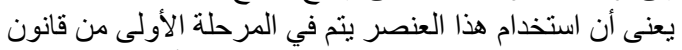
تاقص الغلة والتي فيها يكون الإنتاج الحدى أكبر الكبر من الإنتاج

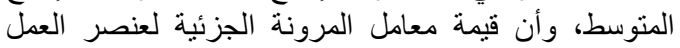

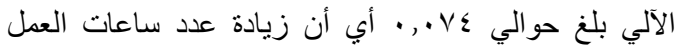

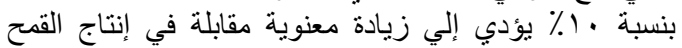

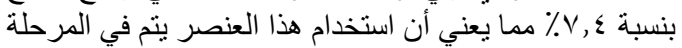

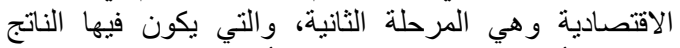

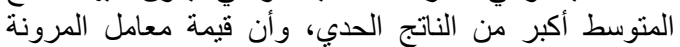

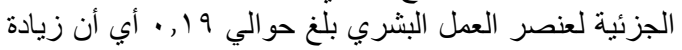

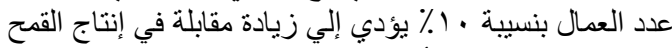
بنسبة 9, 1 ٪ مما يعني أن استخدام هذا العنصر يتم في المرحلة 
Al-Banani et al. / Archives of Agriculture Sciences Journal 4(3) 1-10, 2021.

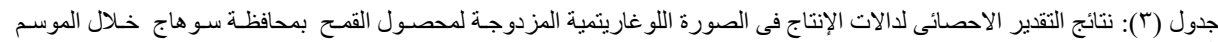

\begin{tabular}{|c|c|c|c|c|c|}
\hline المعادية & 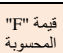 & معالم التحديد & المبـــادلـة & الانحدارة & \\
\hline ' & १, ६० & $r r, q$ & 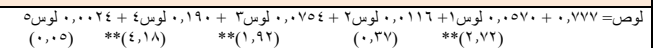 & مثعد & \multirow{2}{*}{ الفنة الأولى } \\
\hline$r$ & $9, \varliminf_{0}$ & $r r, \lambda r$ & 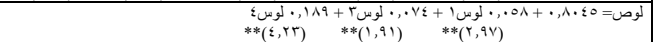 & مرطي & \\
\hline r & rq,17 & $r \varepsilon, \gamma$ & 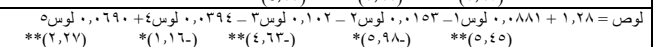 & متعد & \multirow{2}{*}{ الفنة الثانية } \\
\hline ؛ & $r q, 17$ & $r \leqslant, 11$ & 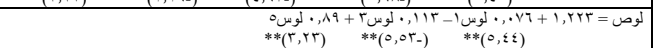 & مرطي & \\
\hline 。 & $r, \cdot r$ & $r r, q$ & 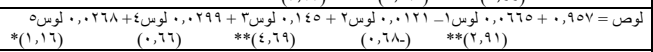 & متعدد & \multirow[t]{2}{*}{ الفنئة الثالثة } \\
\hline$\uparrow$ & $r, \cdot r$ & $v 1, \cdot 1$ & 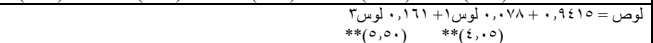 & 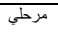 & \\
\hline v & $10, r v$ & $r \cdot, r$ & 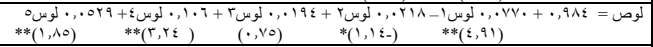 & متعد & \multirow[t]{2}{*}{ 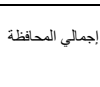 } \\
\hline$\wedge$ & $10, r v$ & $r \cdot r \cdot r$. & 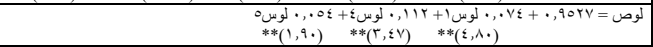 & مرطي & \\
\hline
\end{tabular}

* معنوى عند مستوى المعنوية 0 . . ، ، ** معنوى عند مستوى المعنوية ا ., . ، المصدر : جمعت وحسبت من بيانات استمارة الاستبيان بعينة الدراسة.

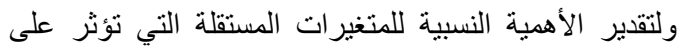

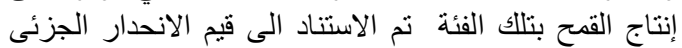

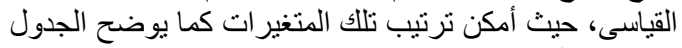

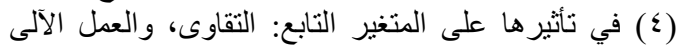

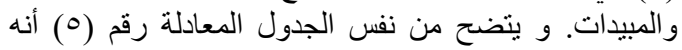

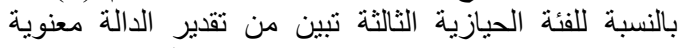

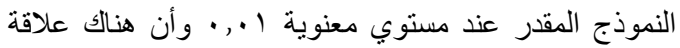

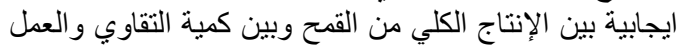

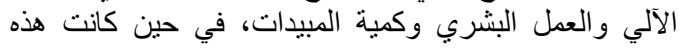

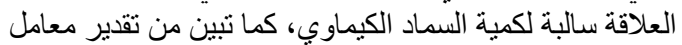

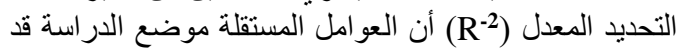

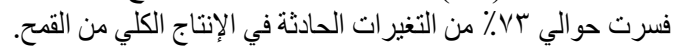

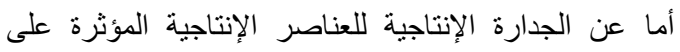

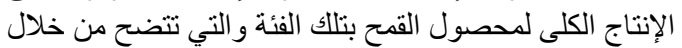

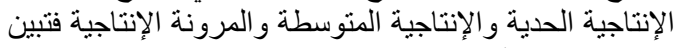

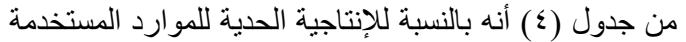

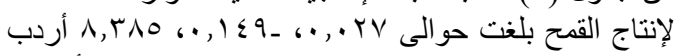

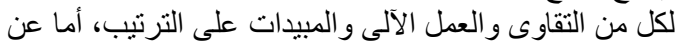

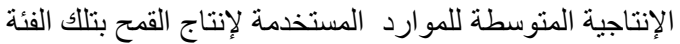

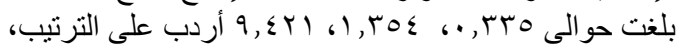

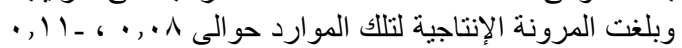

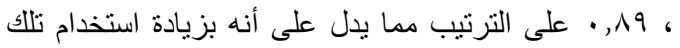

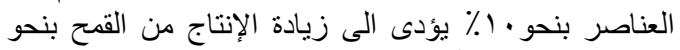

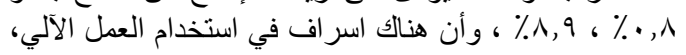

جدول (ع): مؤشر ات الجدارة الإنتاجية وترتيب المتغير ات المسنقلة وأهميتها في التأثير على المتغير التابع بألفئات الحيازية بمحافظة سوهاج

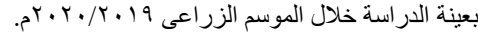

\begin{tabular}{|c|c|c|c|c|c|c|}
\hline \multicolumn{2}{|c|}{ معامل الانحدار الجزئى القياسى } & \multirow{2}{*}{ المرونة الإنتاجية } & \multirow{2}{*}{ الإنتاجية المتوسطة } & \multirow{2}{*}{ الإنتاجية } & \multicolumn{2}{|l|}{ بيـــــــان } \\
\hline الترتيب & 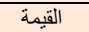 & & & & & الفئات \\
\hline 1 & $\cdot, T V Y$ &., .7 & $\cdot, r+q$ & , ,.r. & |الثتقاوى & \\
\hline$r$ & $0, .91$ & $\cdot, \cdot \mathrm{V}$ & $1, r 00$ & $\cdot, .90$ & العمل الآلي & 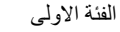 \\
\hline $\bar{r}$ & $\cdot, E Y Y$ & $\cdot, 19$ & $\cdot, V \leqslant 7$ & $\cdot, 1 \leqslant r$ & العمل البشرى & \\
\hline$T$ &., 911 & $\cdot, \cdot \mathrm{A}$ & $\cdot$, rro &.,. $\mathrm{TV}$ & التقاوى & \\
\hline$r$ & $\cdot, Y_{\cdot} \mathrm{V}_{-}$ & $\cdot, 11 \ldots$ & $1, r o \xi$ &., $1 \leqslant 9$ & العمل الآلي & الفئة الثانية \\
\hline$r$ & $\cdot, 1 \wedge \varepsilon$ & $\cdot, \wedge 9$ & $9, \sum Y T$ & $\lambda, r \wedge 0$ & المبيدات & \\
\hline 1 & 1,10 & $\cdot, \cdot 1$ & $\cdot, \Gamma \leqslant \varepsilon$ & $\cdot$, . YA & التقاوى & لفئة الثبالثة \\
\hline r & $\cdot, 497$ & $\cdot, 17$ & 1, ror & $\cdot, Y 17$ & ل العمل الآلي & الهنة التصلدة \\
\hline 1 & $\cdot, \lambda \cdot r$ & $\cdot, \cdot \mathrm{V}$ & $\cdot, r \leqslant \cdot$ & $\cdot, \cdot Y \xi$ & |الثتقاوى & \\
\hline$r$ & $\cdot$, rOA & $\cdot, 11$ & $\cdot, \mathrm{V} \leqslant \mathrm{V}$ & $\cdot, \cdot$ Ar & العمل البشرى & إجمالى المركز \\
\hline$r$ & $\cdot, \ldots 9$ &., .0 & $9, \pi 71$ & $\cdot, \leqslant 71$ & المبيدات & \\
\hline
\end{tabular}

المصدر: جمعت وحسبت من الجدول رقم (r). (ب).

كمية التقاوي بنسبة • (1 يؤدي الي زيادة مقابلة في إنتاج

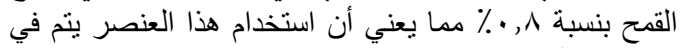

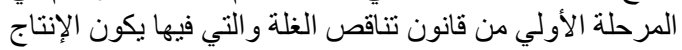

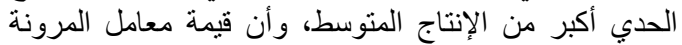

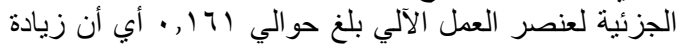
عدد ساعات العمل بنسبة ـ ( ٪ يؤدي الي زيادة مقابلة في إنتاج

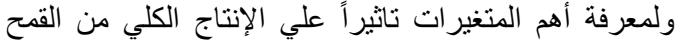

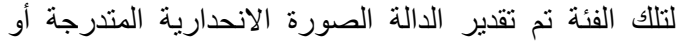

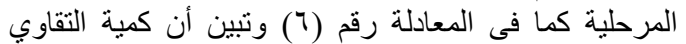

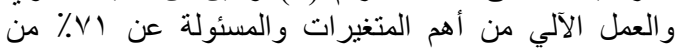

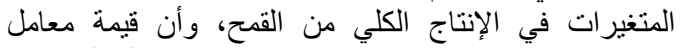

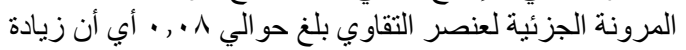




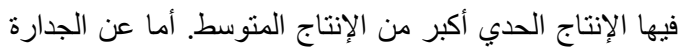

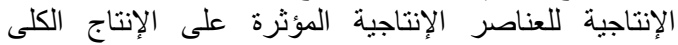

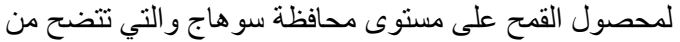
خلال الإنتاجية الحدية والإنتاجية المتوسطة والماتية المرونة الإنتاجية

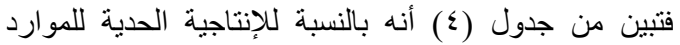

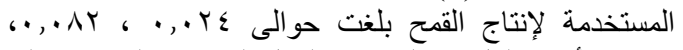

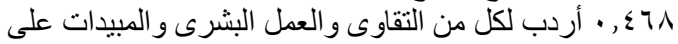

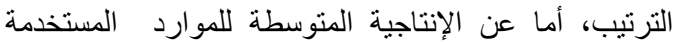

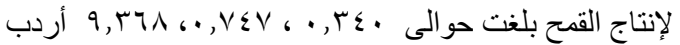

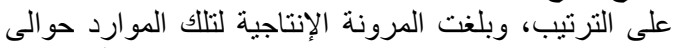

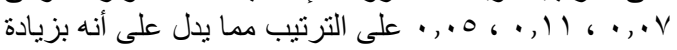

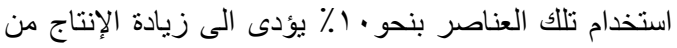

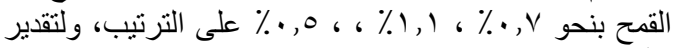

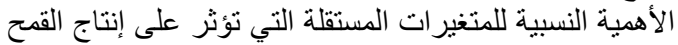

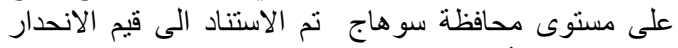

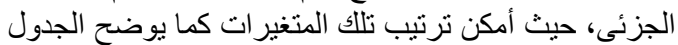

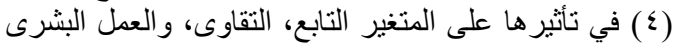

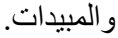

\section{بنة التقدير الإحصائي لدالات التكاليف الإنتاجية على مستوى}

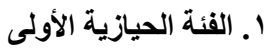

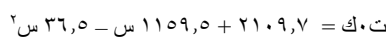

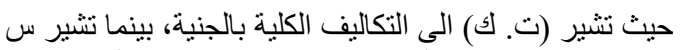

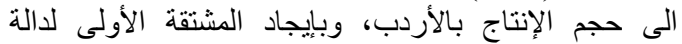
التكاليف الكلية نحصل على دالة التكاليـــ الحديـة:

$$
\text { wrr-1109,0 = }
$$

وبقسمة دالة التكاليف الكلية على حجم الإنتاج (س) نحصل على دالة التكاليـف المتوسطة:

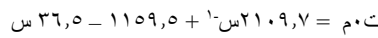

وبتقدير الحجم الأمثل للإنتاج أو حجم الإنتاج المدني للإنكاليف

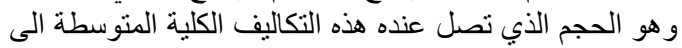

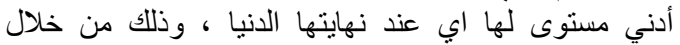

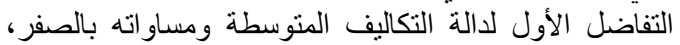
تبين أنه لم يتفق مع الأنطق التصـادياً واحصائياً.

\section{r الفئة الحيازية الثانية}

ت

$$
r, q=0 \quad \cdot, r=r-J
$$

حيث تشير (ت. ك) الى التكاليف الكلية بالجنية، بينما تشير س

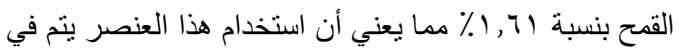

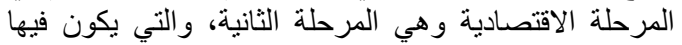

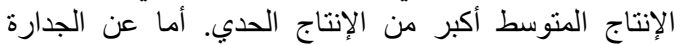

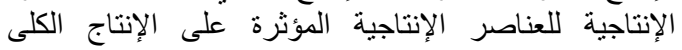

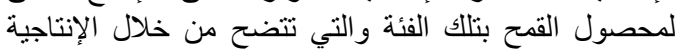

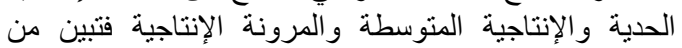

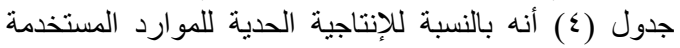

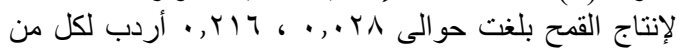

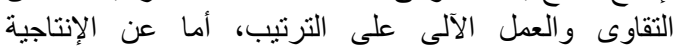

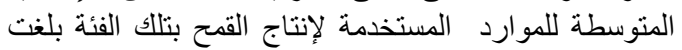

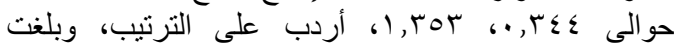

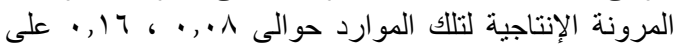

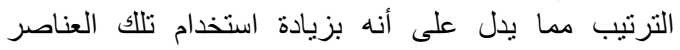

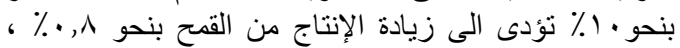

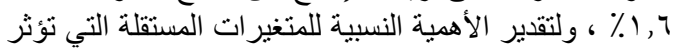

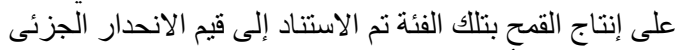

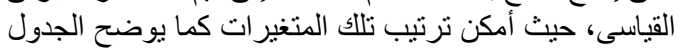

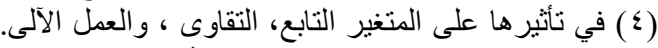

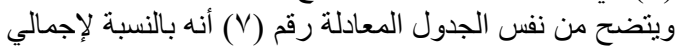

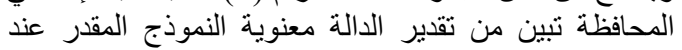

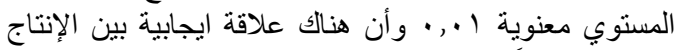

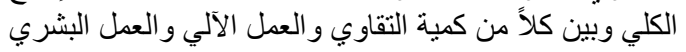

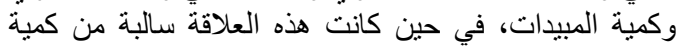

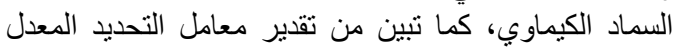

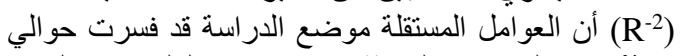

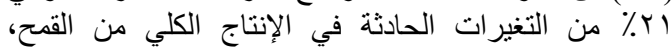

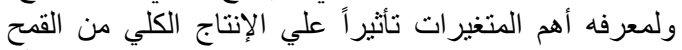

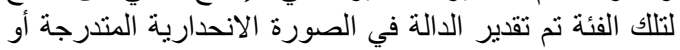

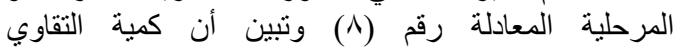

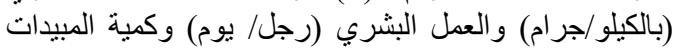

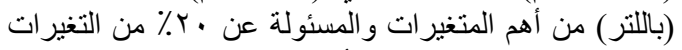

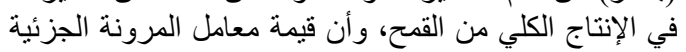

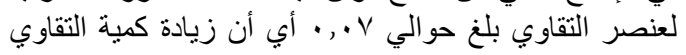

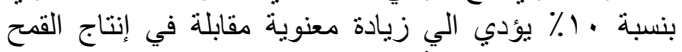

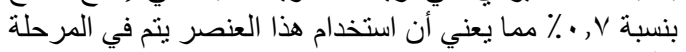

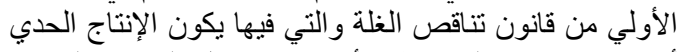

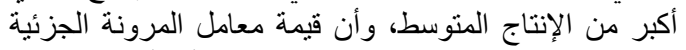

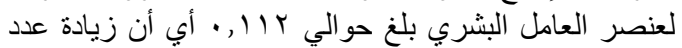

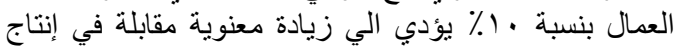

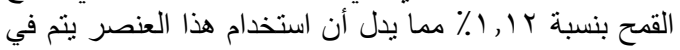

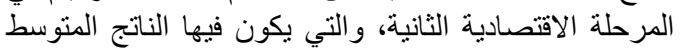

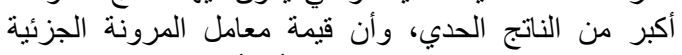

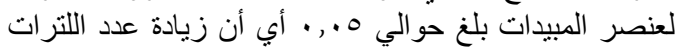

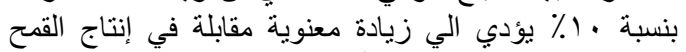

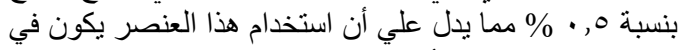
المرحلة الاقتصادية الأولي من قانون تناقص الغلة الغنا الني يكون 


$$
\omega r T M T+71191, r_{-}=\tau \cdot \omega
$$

وبقسمة دالة التكاليف الكلية على حجم الإنتاج (س) نحصل على دالة التكاليـف دالـ المتوسطة : س

ولتقدير الحجم الأمثل للإنتاج أو حجم الإنتـاج المـدني للتكـاليف

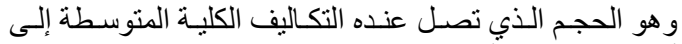

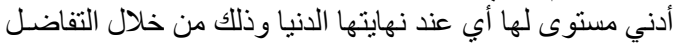

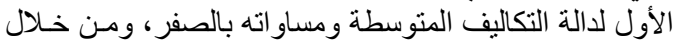

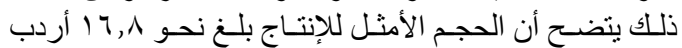

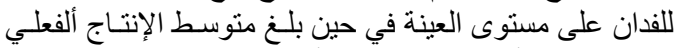

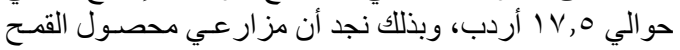

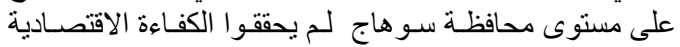

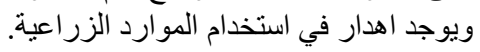

ثالثا: معايير الكفاعة الاقتصادية لمزارعى القمح بعينة الار اسةة بمحافظة سوهاجيز

يتناول هذا الجزء تطبيـق بعض المعـايير الاقتصـادية المطلقـة

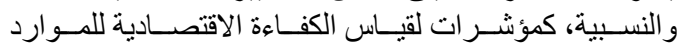

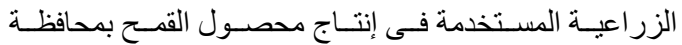

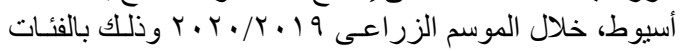

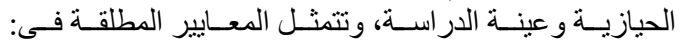

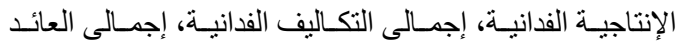

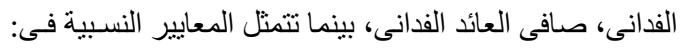

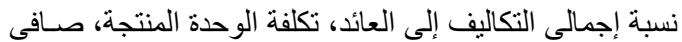

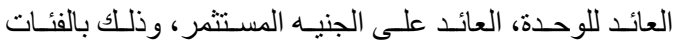

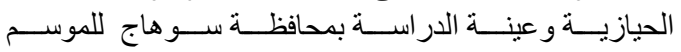

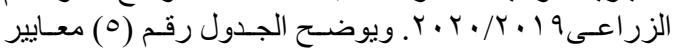

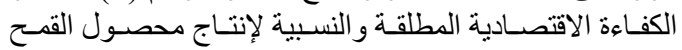

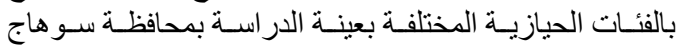

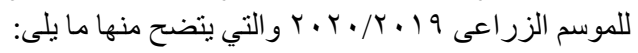

أ. المعاييز المطلقة

فيمـا يتعلـت بمعيـار الإنتاجيـة الفدانيـة تبـين أن مزار عـي الفئة

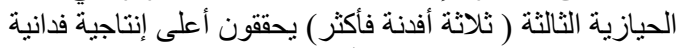

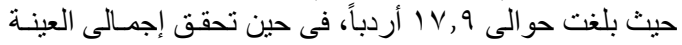

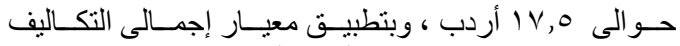

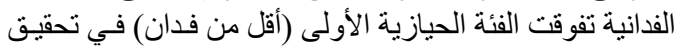

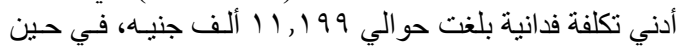

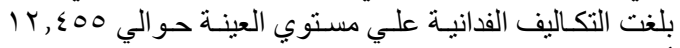

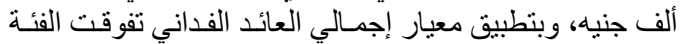

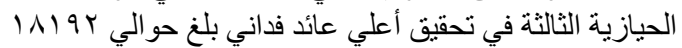

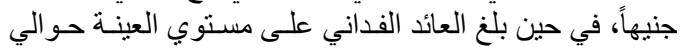

الى حجم الإنتاج بالأردب، وبإيجاد المشتقة الأولى لدالة التكاليف الكلية نحصل على دالة التكاليــــ الحديـة:

$$
\text { w rosts + soros - = }=
$$

وبقسمة دالة التكاليف الكلية على حجم الإنتاج (س) نحصل

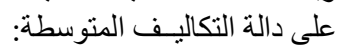

m IrqIV+ soros) - '- ت

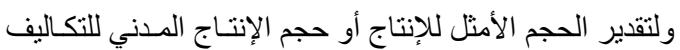

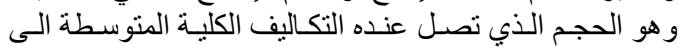

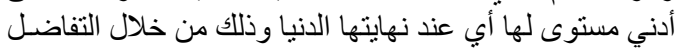

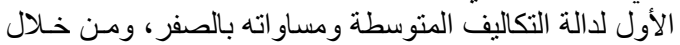

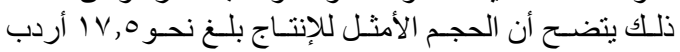
للفدان بالفئة الحيازية الثانية في حين بلغ متوسط الإنتاج الفعلي الفي

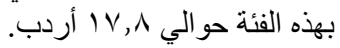

r. الفئة الحيازية الثالثة

$$
\begin{aligned}
& \text { ت. } \\
& \text { • }, \lambda=\omega
\end{aligned}
$$

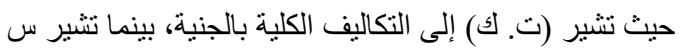

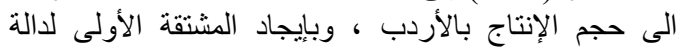

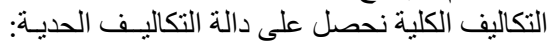

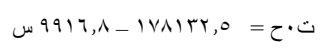

وبقسمة دالة التكاليف الكلية على حجم الإنتاج (س) نحصل على دالة التكاليـف المتوسطة:

$$
\text { تص }
$$

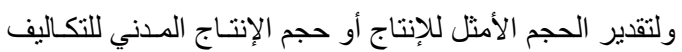

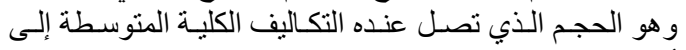

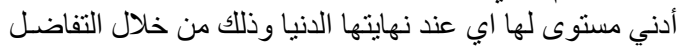

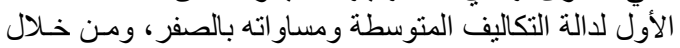

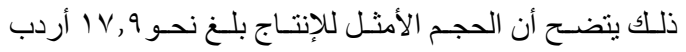
للفدان بالفئة الحيازية الثالثة في حين بلغ الغين متوسط الإنتاج الفعلي

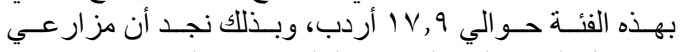

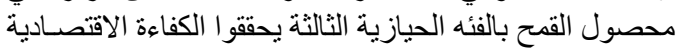
في استخدام الموارد الزر باعية.

$$
\text { ع. على المستوى الإجمالى للعينة }
$$

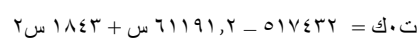

$$
r, \varepsilon=r^{\prime} \quad \cdot, \cdot \varepsilon=r_{-}
$$

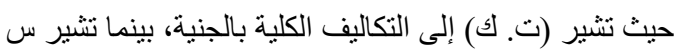

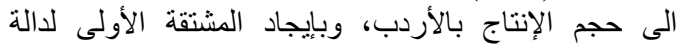

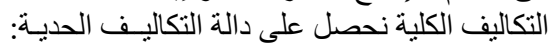




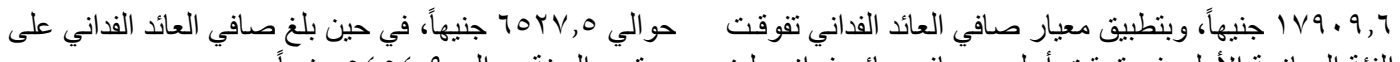

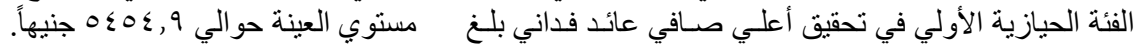

\begin{tabular}{|c|c|c|c|c|c|c|c|c|}
\hline \multicolumn{4}{|c|}{ |المعايير النسبية } & \multicolumn{4}{|c|}{ المعايير المطلقة } & \\
\hline 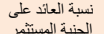 & 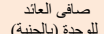 & التكلفة الوحتدة: & التكاليف/العائد & الفانزافى العائان. & 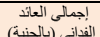 & الإمالمى التكليف & لإنتأجية الفانية & \\
\hline $1,0 \lambda$ & $r Y Y, r Y$ & $7 \leqslant Y, r \xi$ & $\frac{(\%)}{\pi, 1 \Lambda}$ & 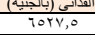 & IYYYT, & $1119 \lambda, 9$ & $1 \gamma, r$ & \\
\hline 1,50 & $Y Y 0,9 Y$ & Yol, : $\varepsilon$ & $\frac{V r, \Lambda O}{}$ & $\xi$ \&Yr, & 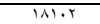 & $1, r \uparrow \uparrow, \eta$ & $\overline{1 V, \lambda}$ & \\
\hline L,r. & $17 \lambda, .1$ & $\Lambda \varepsilon \Lambda, r \cdot$ & $\lambda r, \xi \mathrm{V}$ & $r \ldots, v, \xi$ & 11194 & $1011 \leqslant, 7$ & $1 v, 9$ & \\
\hline $1, \xi \xi$ & $r \mid 1, y)$ & $y / 1, y$. & $79,0\}$ & $0 \leqslant 0 \leqslant, 9$ & $179 \cdot 9,9$ & $T \leqslant 0 \leqslant, Y$ & $1 v, 0$ & \\
\hline
\end{tabular}

* التكاليف الفدانية متضمنة الإيجار. المصدر: جمعت وحسبت من بيانات عينة البحث..

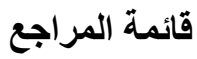

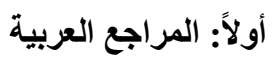

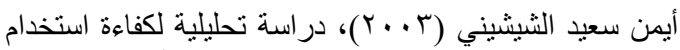

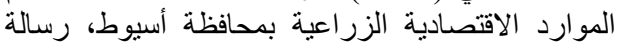

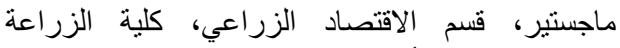
بالقاهرة، جامعة الأزهر، جمهورية مصر العربة العربية.

صلاح على صالح (991 (1))، كفاءة استخدام الموارد الزر اعية

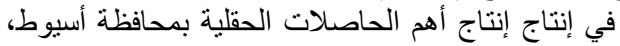

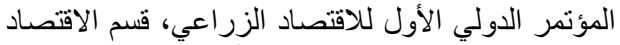

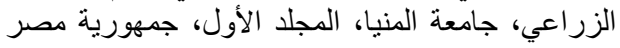

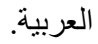

عبد النبي عبد الحليم الثريف (ب99 (1))، تحليل مقارن للكفاءة

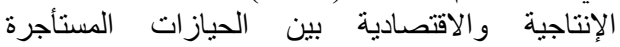

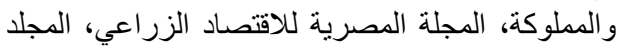

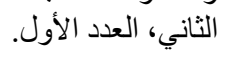

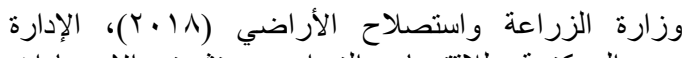

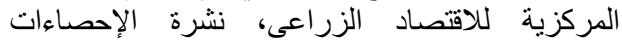

$$
\text { الزر اعية، جمهورية مصر العربية. }
$$

\section{ثانياً: المراجع الإنجليزية}

Frich, R. (1965), Theory of Production, Dordrecht, Holland, D. Reidel Pub. Co.; Rand McNally, Chicago, USA, pp. 41.

Leftwich, R. H. (1996), The price system and resource allocation, $3^{\text {rd }}$ edition, Holt, Rinehart and Winston, USA.

Porkin, M. (1996), Microeconomics, Addison Wesley Publishing Company, New York, USA.

\section{ب. المعايير النسبية}

من خلال تطبيق معيار نسبة التكاليف من العائد تبين أن أدنى التي

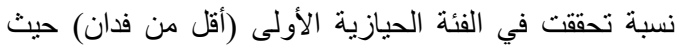

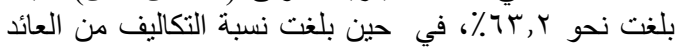

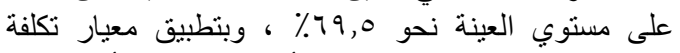

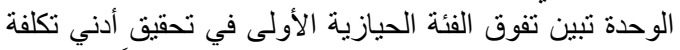

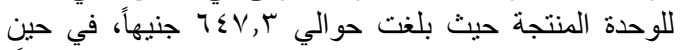

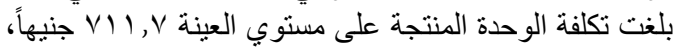

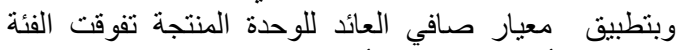

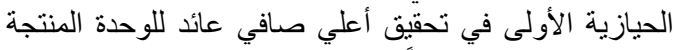

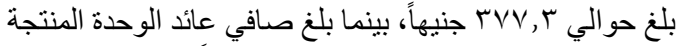

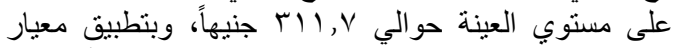

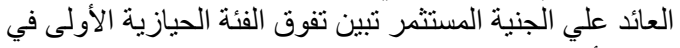

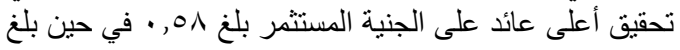
هذا العائد الاستثماري على مستوي العينة حو الي ع ؟ ــ . .

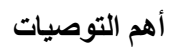

1. ضرورة الاهتمام بالعمليات الزر اعية والمعاملات

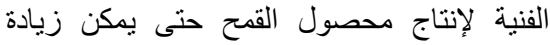
متوسط إنتاجية الفدان منه خاصة في ظل استخدام التقاوي المحسنة و المهجنة.

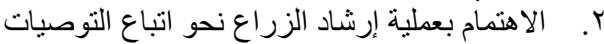

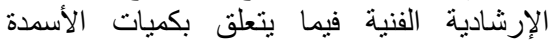
الموصي بها للفدان. - الفئ.

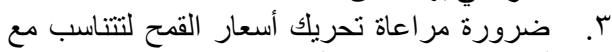

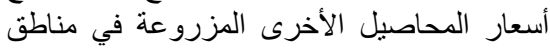

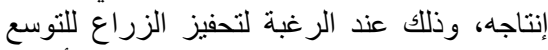

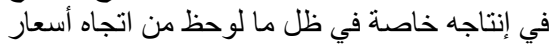

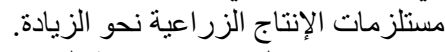

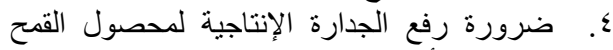
باستتباط الأصناف الجيدة عالية الإنتاجية في الوقت لفحت

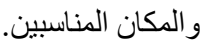

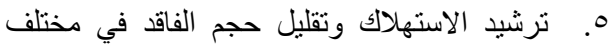
مر احل الإنتاج و الاستهلاك المختلفئ. 